\title{
EDUCAÇÃO EM TEMPO INTEGRAL EM UMA ESCOLA DE EDUCAÇÃO INFÂNTIL DE SANTA MARIA-RS: DIÁLOGOS POSSÍVEIS
}

\author{
FULL TIME EDUCATION IN AN EARLY CHILDHOOD EDUCATION \\ SCHOOL OF SANTA MARIA-RS: POSSIBLE DIALOGUES
}

\author{
Natália Desconsi de ANDRADE ${ }^{1}$ \\ Andressa WIEBUSCH ${ }^{2}$ \\ Taciana Camera SEGAT ${ }^{3}$
}

\begin{abstract}
RESUMO: Esta pesquisa trata sobre a Educação em Tempo Integral na Educação Infantil de uma Escola Municipal da cidade de Santa Maria - RS. Tem como objetivo compreender a proposta educativa realizada com as crianças que permanecem em Tempo Integral na escola. A metodologia utilizada foi a pesquisa qualitativa, a qual objetivou compreender da organização do trabalho docente e da equipe gestora, em especial da direção, tendo em vista o Turno Integral. Por fim, apontamos que com o aumento do número de instituições para atender as crianças de zero a cinco anos, poderíamos implementar melhor qualidade no atendimento às necessidades da população do município. Essa é uma luta longa e muito árdua da sociedade em prol da garantia do direito ao acesso das crianças na escola em Turno Integral.
\end{abstract}

PALAVRAS-CHAVE: Educação em tempo integral. Educação infantil. Gestão escolar. Políticas públicas.

ABSTRACT: This research is about Full Time Education in Early Childhood at a Municipal School in Santa Maria - RS. It aims at analyzing the educational planning for children that stay Full Time at school. It was a qualitative research which focused on the teaching work organization and the management team, mainly the principal, in relation to Full Time classes. A higher number of institutions for children aged from zero to five years old could offer a better quality in the assistance to the necessities of the local population. This is a long and very hard struggle of the society in favor of the right for children to have access to Full Time education.

KEYWORDS: Full time education. Early childhood education. School management. Public policies.

\footnotetext{
${ }^{1}$ Especialista em Gestão Educacional (UFSM) e professora de educação infantil da rede privada de Santa Maria - RS. E- mail: nataliadesconsi@gmail.com

${ }^{2}$ Mestre em Educação UFSM. Tutora/professora no Curso de Pedagogia - Modalidade à distância da Universidade Aberta do Brasil (UAB/UFSM). Email: andressagpfope@ gmail.com

3 Docente do Curso de Pedagogia da Universidade Federal de Santa Maria (UFSM). E-mail: tcamerasegat@gmail.com
} 


\section{A educação em tempo integral na educação infantil}

Este estudo tem como objetivo investigar como a equipe gestora de uma EMEI tem planejado e organizado o trabalho docente em turmas de crianças que permanecem na escola em Tempo Integral. Assim, a questão problema estudada é: qual a proposta de trabalho elaborada e implementada para as crianças que frequentam a escola em Tempo Integral na Educação Infantil?

Nesse sentido, buscou-se conhecer as ações da gestão escolar e as ações da professora com a turma de Turno Integral na Educação Infantil, como um aspecto relevante na construção do processo educacional nos espaços da escola. Estes espaços constituem-se na sala de aula, pátio interno, pracinha, pátio externo com área livre para brincar, andar de bicicleta, correr, interagir. As crianças que ocupam esses espaços possuem idades entre 3 (três) e 4 (quatro) anos.

\section{Educação em tempo integral: políticas públicas e gestão escolar}

Nesse estudo, apresentamos elementos da contextualização histórica e política da Educação em Tempo Integral, a diferença entre a Educação em Tempo Integral e a Educação Integral, buscando assim sua compreensão e a integralidade das duas dimensões: Educação Integral e Educação em Tempo Integral. Também, traz-se a gestão escolar como equipe de professores, funcionários, pais e alunos os quais estabelecem estratégias para a construção dos espaços escolares de Turmas Integrais, não esquecendo que a prioridade são as crianças e o bem-estar delas.

Trazendo a ideia de Educação em Tempo Integral e Educação Integral destacamse algumas perguntas que encaminham as reflexões aqui salientadas: quais as principais diferenças consideradas em relação às turmas de turno único? Há diferença na organização dos tempos e espaços das turmas de turno único? Quais? Por quê?

$\mathrm{Na}$ década de 30 a escola pública passou a ter responsabilidades que não eram vistas como atividades pedagógicas, como cuidar, fazer carinho, dar amor, atenção. Com isto, salienta-se o documento ${ }^{1}$ Série Mais Educação - Educação Integral: texto referência para o debate nacional, que relata:

Educação integral, uma educação que promove o desenvolvimento da criança e do adolescente em suas múltiplas dimensões, considerando o 
corpo, a mente e a vida social, no sentido da construção da cidadania, do sujeito autônomo, crítico e participativo (BRASIL, 2009, p. 19).

Assim, podendo tornar-se um contexto mais interessante à realidade das crianças, apresenta o universo escolar e a importância deste para as diversas aprendizagens que são capazes de desenvolver.

Contextualizando a Educação em Tempo Integral, no Art. 34 da LDB, a jornada escolar é considerada como o período em que a criança está sob responsabilidade da escola, sendo progressivamente ampliado o período de permanência na escola. Na Educação Infantil, o Tempo Integral na escola deve ser pensado para que as crianças possam brincar, alimentar-se bem, explorar os ambientes da escola, em que se busca uma educação de qualidade para as crianças, aprender com as tecnologias e as possibilidades de uso de materiais diversos, potencializando a diminuição da evasão escolar.

Neste contexto, a Educação Integral e a Educação em Tempo Integral são historicamente articuladas, pois surgem da necessidade de se oferecer um atendimento educacional às crianças, filhos de mulheres trabalhadoras, que não tinham condições financeiras de pagar por esse serviço. Com isso, começaram a surgir as creches públicas, locais em que o cuidado e a educação passaram a tornarem-se cada vez mais acessíveis e começou a se pensar em uma Educação Integral da criança como um todo, sendo desenvolvimento global do ser humano.

Sendo assim, pensar os processos, as experiências e as experimentações vividas na escola possibilita perceber que não é somente o tempo em que as crianças estão na escola que precisa valer a pena, mas todo o tempo de vida da criança precisa ser prazeroso e cheio de novas descobertas e aprendizados. A organização do tempo e espaço para a criança, envolve a gestão da escola, onde todos estão envolvidos. Partindo dessa compreensão a autora enfatiza que a gestão da escola:

Corresponde a dar vez e voz e envolver na construção e implementação do seu projeto político-pedagógico a comunidade escolar como um todo: professores, funcionários, alunos, pais e até mesmo a comunidade externa da escola, mediante uma estratégia aberta de diálogo e construção do entendimento de responsabilidade coletiva pela educação. (LÜCK, 2008b, p.81)

Nessa perspectiva, da gestão escolar o objetivo é que todos possam estar envolvidos com a escola, cada um com sua responsabilidade, proporcionando a 
integralidade entre os envolvidos no desenvolvimento da instituição, na participação dos pais e na Educação. Sendo assim, as instituições escolares criam estratégias para a construção de uma identidade para a escola, a qual pode caracterizar-se como construtora de prática educativas lúdicas, receptora, colaboradora de aprendizagens, e acolhedora, assim estabelecendo meios/modos para sua organização e funcionamento.

Com a ampliação da jornada escolar, é preciso que os tempos e os espaços escolares sejam planejados de acordo com as necessidades educativas das crianças. Coelho (2011) traz a ideia de ampliação da jornada escolar tendo como objetivo a busca de melhor qualidade do ensino, sendo esta a partir do olhar de alunos. Durante esse Tempo Integral que a criança se encontra na escola ela estará imaginando, criando e desenvolvendo muitas aprendizagens. Desta forma, a gestão escolar é peça fundamental na orientação para a qualidade dos processos vividos pelas crianças na escola. Pois, a "a gestão visa, em última instância, a melhoria das ações e processos educacionais, voltados para a melhoria da aprendizagem dos alunos e sua formação, sem o que aquela gestão se desqualifica e perde a razão de ser." (LÜCK, 2008b, p. 15-16).

Neste processo, é fundamental para o desenvolvimento das crianças as brincadeiras e as interações, previstas na DCNEI (2010) como eixos atravessadores para a construção do conhecimento das crianças. A educação precisa ser pensada primeiramente para as crianças da Educação Infantil, pois é nesse espaço que estão vivenciando as aprendizagens escolares. Dessa forma, a educação passa a ser desenvolvida com base no interesse em aprender novos conhecimentos.

O espaço escolar é central na oferta da escolaridade básica de direito de crianças e adolescentes. A escola tem importância fundamental para que as novas gerações possam dominar conhecimentos e habilidades para viver e se mover no mundo (UNICEF, 2011, p. 36).

A Gestão Escolar precisa ter como meta para o Turno Integral: desenvolver momentos de aprendizagens por meio da imaginação, das interações, das brincadeiras, das atividades lúdicas e atrativas, as quais motivam o interesse por aprender e o prazer em estar no ambiente escolar. Sendo assim, o educador precisa organizar o seu planejamento, articulando os dois turnos fazendo um planejamento diário em que sejam contemplados os diferentes espaços e tempos vividos ao longo do dia pelos sujeitos.

Na Constituição Brasileira de 1988, o inciso XXV do art. $7^{\circ}$, relativo a Direitos Sociais, esclarece que: 
Mesmo não havendo, explicitamente, a obrigatoriedade, infere-se que a oferta de Educação Infantil em tempo integral se constitui como um direito dos trabalhadores cujos filhos e dependentes de até seis anos de idade dela necessitem (BRASIL, 1998).

Sendo assim, é direito assegurado dos filhos dos trabalhadores ter o acesso ao Turno Integral nas escolas públicas municipais na Educação Infantil. Todos, sem distinção, deveriam ter seu direito respeitado, ter escolas, turmas e vagas disponíveis não só a "quem realmente precisa", como é mencionado pela diretora da escola na realização da entrevista, mas a todos, pois se constitui em um direito assegurado pela Constituição Federal do Brasil.

Segundo as Diretrizes Curriculares Nacionais para a Educação Infantil (Parecer CNE/CEB no 22/98), a Educação em Tempo Integral, no que se refere ao cuidado e educação das crianças, alerta sobre a necessidade de ser realizada, conforme as necessidades dos educandos, assim como de suas famílias, as quais precisam deste atendimento para que possam trabalhar tranquilos, podendo confiar na escola em que seu filho aprende, ensina, brinca, experimenta, vivencia, se diverte.

É necessário também que haja planejamento e professores qualificados para o funcionamento das atividades pedagógicas. A formação continuada dos profissionais complementa a aprendizagem tanto do educador como do educando, trazendo sempre conhecimentos e habilidades da atualidade. Para isso, Kramer (1997) destaca que é preciso o acesso ao processo de conhecimento adquirido ao longo de sua profissionalização, podendo assim repensar suas práticas no dia a dia em suas vivências, reconstruindo-se pessoal e profissionalmente, possibilitando que seus alunos também se reconstruam.

\section{Metodologia}

Nesse estudo, utilizamos a abordagem qualitativa, a qual tem como característica a coleta de dados no ambiente natural, podendo assim buscar informações, identificar fatos e ações. O pesquisador é quem vai em busca dos elementos necessários para que a pesquisa possa ser desenvolvida. Pois, a pesquisa qualitativa:

Compreende um conjunto de diferentes técnicas interpretativas que visam a descrever e a decodificar os componentes de um sistema 
complexo de significados. [...] Em sua maioria, os estudos qualitativos são feitos no local de origem dos dados [...] (NEVES, 2015, p. 01).

Sendo assim, a pesquisa qualitativa possui maior ênfase e qualidade por analisar o ambiente original onde são coletadas as informações para o estudo de um determinado assunto. Ainda possibilita a interação e relação com o meio que está sendo pesquisado.

Esta pesquisa teve como objetivo investigar a proposta educativa implementada com crianças que permanecem em Tempo Integral na escola, tencionando compreender os movimentos das práticas pedagógicas e dos sujeitos que vivenciam.

Tentando compreender o trabalho educativo realizado nas escolas que atendem turmas de Tempo Integral, a pesquisa foi realizada em uma Escola de Educação Infantil do Município de Santa Maria - RS, localizada em Bairro afastado do centro da Cidade, possuindo aproximadamente 300 (trezentos) alunos. A escola recebe crianças desde o Berçário a partir dos 6 (seis) meses até o Pré com 5 (cinco) anos. Ao total são 7 (sete) turmas na parte da manhã e 7 (sete) turmas na parte da tarde, as quais possuem os níveis Berçário, Maternal e Pré.

Para a coleta de dados, optou-se por entrevistas semiestruturadas, que favorecem não somente a descrição, mas a compreensão da totalidade a ser investigada. Foram entrevistadas as seguintes pessoas: a diretora da escola, uma criança da turma de maternal I que participa do Turno em Tempo Integral, professora dessa turma e uma mãe de uma criança, buscando compreender as diferentes concepções acerca da turma de tempo integral.

\section{Análise: discussões acerca dos diálogos}

A análise permitiu identificar quatro eixos de análise, os quais foram denominados: organização escolar, planejamento, necessidade familiar, e o tempo escolar.

A organização escolar destaca-se de acordo com a entrevista realizada com a diretora da EMEI, a qual menciona que "gostaria muito de ter a possibilidade de abrir mais turmas integrais na escola", mas são apenas planos da gestão escolar, pois não há espaço físico na instituição para atender as demais turmas integrais. Há muitos pais, moradores dos arredores que gostariam de ter a oportunidade do turno integral para seus/suas filhos(as), mas somente alguns conseguem vagas. 
Dessa forma, na entrevista com a diretora da escola foi possível compreender um pouco mais a maneira como a distribuição das vagas é organizada. A diretora enfatiza que:

[...] procurou-se privilegiar o Berçário integral porque é a única Escola da Região sul de Santa Maria que atende essa faixa etária, de ser a partir de 6 meses. Então a gente procura manter assim essa estrutura que a gente tem de atendimento para Berçário e Maternal I (Diretora da escola).

A intenção da diretora é dar oportunidade para aquele nível que é o mais procurado e o que é menos atendido na comunidade escolar. Evidente que é mais procurado porque a comunidade tem conhecimento que nos outros níveis não existe a possibilidade, o que significa dize que a procura não está ligada a necessidade da comunidade, mas ao próprio histórico da instituição. A diretora afirma ainda que para os demais níveis, há outra escola que atende essas crianças, confirmando a triste e malvada história da educação infantil, uma vez que a outra escola mencionada é um espaço criado e gestado por moradores da comunidade para receber essas crianças que aos 3 anos perdem o direito a escola pública de educação infantil:

Aqui na comunidade tem uma Escola Comunitária e já existe há alguns anos... Alguns alunos nossos estão aqui de manhã, almoçam e a tarde vão pra essa Escola Comunitária, só que ali eles não atendem específico bebê, mais são as crianças a partir dos 2 anos e meio 3 anos, são maiores. Então assim, algumas famílias buscam essa escola pra suprir essa falta de quem cuidar a criança no outro turno. E tem muitos casos que ficam com os irmãos, as famílias ajudam muito. Na comunidade as famílias são bem numerosas, então acaba que alguém da família assume essa criança até a mãe chegar do trabalho (Diretora da escola).

Infelizmente, vive-se a triste realidade de crianças que já estão matriculadas em uma escola de Educação Infantil e que, por falta de espaço físico adequado na instituição para que possam acolher a todas as crianças da comunidade escolar nas turmas de Turno Integral, perdem o direito de permanecer o tempo que necessitam por falta de vagas. Por serem de uma região de vulnerabilidade social, o direito a Educação Infantil gratuita, de qualidade, de tempo integral deveria ser prioridade para o pode público.

De acordo com o Plano Nacional de Educação (PNE, 2014), para as escolas que possuem crianças em tempo integral, é necessário que sejam aprimorados os espaços e 
as condições de aprendizagens, sendo que é dever do governo do Estado e da Prefeitura do Município colaborar com este crescimento.

Instituir, em regime de colaboração, programa de construção de escolas com padrão arquitetônico e de mobiliário adequado para atendimento em tempo integral, prioritariamente em comunidades pobres ou com crianças em situação de vulnerabilidade social (Estratégia 6.2); institucionalizar e manter, em regime de colaboração, programa nacional de ampliação e reestruturação das escolas públicas, por meio da instalação de quadras poliesportivas, laboratórios, inclusive de informática, espaços para atividades culturais, bibliotecas, auditórios, cozinhas, refeitórios, banheiros e outros equipamentos, bem como da produção de material didático e da formação de recursos humanos para a educação em tempo integral (Estratégia 6.3); e adotar medidas para otimizar o tempo de permanência dos alunos na escola, direcionando a expansão da jornada para o efetivo trabalho escolar, combinado com atividades recreativas, esportivas e culturais (Estratégia 6.9) (BRASIL, 2014, p. 29).

Infelizmente nossa realidade escolar é precária, pois a maioria das escolas públicas não possui todos esses espaços e meios de tecnologia disponível às crianças. Os espaços não são totalmente adequados para atender aos pequenos que participam do turno em tempo integral da educação infantil.

Dependendo das situações, há casos em que a diretora da Escola consegue remanejar para que a criança não perca o vínculo com a escola, ao concluir o nível de Maternal I. A situação é grave, visto que algumas crianças acabam por perder o direito de permanecer em turno de Tempo Integral na escola. Com isso, a diretora da escola explica que:

Sempre digo para os pais, não precisam vocês procurar outro tipo de recurso, coisas que a gente pode resolver aqui. Se tu conhece a família há anos como conheço, de crianças que estão aqui desde bebês, então ele vai ficar integral, mas são alguns casos, porque a gente não tem como abrir pra todos. São crianças que estão aí desde o Berçário, são famílias que a gente sabe que estão lutando para dar um futuro melhor pra aquela criança (Diretora da escola).

Dessa forma, alguns apenas são privilegiados, nem todos conseguem ter esta prioridade, no entanto o acesso à Educação é direito de todos. A Gestão Escolar tem tentado dinamizar e compreender as situações que ocorrem, buscando resolvê-las com coerência, visando solucionar os problemas que vão surgindo, mas nem sempre é possível. Assim, descrito na Meta 6 do PNE: 
Nesse sentido, garantir educação integral requer mais que simplesmente a ampliação da jornada escolar diária, exigindo dos sistemas de ensino e seus profissionais, da sociedade em geral e das diferentes esferas de governo não só o compromisso para que a educação seja de tempo integral, mas também um projeto pedagógico diferenciado, a formação de seus agentes, a infraestrutura e os meios para sua implantação (BRASIL, p. 28, 2014).

O empenho da Gestão Escolar referente às turmas de Turno Integral é muito importante para o desenvolvimento e o crescimento das ações realizadas e propostas pelas professoras. A parceria entre elas é fundamental para que as crianças se sintam bem na escola, aprendam brincando e se divertindo, sintam-se bem, compreendendo que existem pessoas que estão ali por elas e com elas, já que seus pais não podem estar.

\begin{abstract}
A gestão, portanto, é que permite superar a limitação da fragmentação e da descontextualização e construir, pela óptica abrangente e interativa, a visão e orientação de conjunto, a partir da qual se desenvolvem ações articuladas e mais consistentes. Necessariamente, portanto, constituir ação conjunta de trabalho participativo em equipe (LÜCK, 2008b, p. 43).
\end{abstract}

É importante mencionar que ao se referir ao Turno Integral, a diretora da escola coloca em evidência as crianças que estão em vulnerabilidade social, as quais precisam que a escola infantil as acolha, pois necessitam de cuidados e incentivos para o seu crescimento, o seu direito à infância, ao brincar, às relações com o outro e ao afeto. Sobre isso, os autores complementam que:

[...] a implementação do tempo integral no âmbito da educação infantil, o que observamos é uma ênfase na ampliação do tempo de permanência das crianças, sobretudo naquelas instituições cujos territórios se encontram em áreas mais vulneráveis decorrentes da pobreza e em função dos chamados "riscos sociais" que ameaçam os direitos das crianças pequenas (ARAÚJO; COELHO; SIQUEIRA, 2015, p. 7).

Para isso, as famílias precisam estar em sintonia com a escola, a fim de que essa parceria possa possibilitar à criança segurança para receber tudo o que ela precisa para desenvolver-se, sendo criança, brincando, aprendendo, tendo carinho e aprendizagens positivas para seu desenvolvimento infantil.

A gente fez um longo trabalho com as famílias, porque antes eles pensavam que "ah vai lá pra cuidar, vai brinca lá, meu filho vai pra brincar...” Daí eles entenderam que ele vai aprender, que existe um trabalho pedagógico todo. E a gente conseguiu passar 
para os pais esse novo conceito de Educação Infantil, que tudo tem um trabalho pedagógico, tem um acompanhamento, um crescimento da criança (Diretora da escola).

Por intermédio da fala da diretora e da professora da turma integral, percebe-se que a escola busca intensificar as relações com as famílias, por meio de conversas, de parceria e de eventos proporcionados pela escola, nos quais é fundamental a presença dos pais para dar entusiasmo aos seus filhos, que fazem parte da escola desde bem pequenos, visto que estes estão iniciando sua vida, para poderem buscar os seus direitos e desenvolver a sua autonomia. Assim, destaca-se a colaboração de todos no meio escolar.

As relações entre a comunidade escolar, pais, professores e gestão escolar tornam-se democráticas quando todos fazem parte das decisões e conquistas da escola e são levadas em consideração às práticas, os valores e os princípios de cada um que compõe a escola como um todo. Tudo isso nos leva a pensar que é necessária a complementaridade de todos os envolvidos na escola, para que seja realizado um trabalho em que todos possam se beneficiar, principalmente as crianças, foco da Educação Infantil.

A respeito do planejamento escolar realizado pela professora da Turma Integral de Maternal I, observou-se que ela busca compreender cada criança em sua particularidade, procurando proporcionar a todas, que passam muitas horas do seu dia com ela, sensações de alegria e satisfação ao estarem na escola. A professora da Turma Integral demonstra necessidade de preocupar-se com o bem-estar das crianças em sala de aula.

São coisas que me preocupam sabe, e flexibilizar a brincadeira, flexibiliza que eles possam viver a infância deles. De eles terem o direito de serem crianças, uma cultura que respeite a infância, que eu possa me lambuzar, que eu possa derrubar as coisas no chão, porque eu estou aprendendo, que eu possa brincar sem ficar pensando que eu tenho que voltar pra sala as $16 \mathrm{~h}$ porque tem outra turma a entrar na pracinha... (Professora da escola).

Dessa forma, percebe-se que a Professora preocupa-se com aquelas crianças e tenta, de alguma forma, satisfazer suas necessidades, suas angústias, seus medos, dando a elas afeto, carinho e muita atenção. Considerando as vivências das crianças na escola, a organização do planejamento demonstra ser lúdica, contemplando a realidade das 
crianças e as percepções observadas pela professora durante o seu contato diário com os pequenos.

O planejamento educativo deve ser assumido no cotidiano como um processo de reflexão, pois, mais do que ser um papel preenchido, é atitude e envolve todas as ações e situações do educador no cotidiano do seu trabalho pedagógico. Planejar é essa atitude de traçar, projetar, programar, elaborar um roteiro pra empreender uma viagem de conhecimento, de interação, de experiências múltiplas e significativas para com o grupo de crianças. Planejamento pedagógico é atitude crítica do educador diante de seu trabalho docente. Por isso não é uma fôrma! Ao contrário, é flexível e, como tal, permite ao educador repensar, revisando, buscando novos significados para sua prática pedagógica. [...] Documentando o processo, o planejamento é instrumento orientador do trabalho docente (OSTETTO, 2000, p. 01).

Planejar é um ato diário. $\mathrm{O}$ educador precisa pensar a prática a ser realizada com seus alunos na escola. Pensar um planejamento para a Educação Infantil é prazeroso, pois instiga a buscar formas de aprender brincando. Nesse contexto, a professora da Turma Integral da escola menciona uma situação ocorrida ao longo de alguns tempos vividos na instituição:

[...] eu vou pra fora, vou pra debaixo duma árvore, vou fazer piquenique, procuro explorar todos os ambientes da escola pra que isso fique diversificado, fique mais divertido, fique mais saudável (Professora da escola).

A professora participante da pesquisa relata ter o objetivo permanente de proporcionar a estas crianças que passam boa parte do seu dia com ela na escola oportunidades de receber afeto, de aprender em diferentes situações, como nas atividades pedagógicas e nas brincadeiras. Em meio a estas situações vão surgindo os planejamentos e os projetos vão sendo criados.

O formigário surgiu assim, a gente passeia muito e foi instigando a curiosidade deles e surgiu uma proposta de Feira de Ciências da SMED. A gente começou a trabalhar a questão da Rainha, da Operária, e de como também funciona a nossa sala, que parece que às vezes a gente é a formiguinha, que a gente carrega tudo junto, a gente faz todas as coisas juntas, todos juntos, e daí nasceu um projeto... e assim que os projetos vão fazendo, e daí eu vou planejando por meio dos projetos (Professora da escola). 
O planejamento surge de acordo com o interesse das crianças de descobrirem as coisas, de ter curiosidade em relação ao que elas vão em busca, ao que veem diferente no pátio da escola, em meio aos seus passeios, suas descobertas nas brincadeiras, na pracinha da escola. Com isso, a professora não deixa passar despercebidas as dúvidas que vão surgindo, instigando ainda mais a curiosidade e a aprendizagem destas crianças da turma de maternal I integral na escola. "Sem dúvida, a elaboração de um planejamento depende da visão de mundo, de criança, de educação, de processo educativo que temos e que queremos: ao selecionar um conteúdo, uma atividade, uma música, na forma de encaminhar o trabalho (OSTETTO, 2000, p. 2)”.

É de acordo com a realidade das crianças e com os interesses delas que surgem os projetos e assim os planos de aula diários, oportunizam a percepções, aos processos de conhecimento e de autonomia. A Educação Integral da criança e o Tempo Integral em que a criança permanece na escola são importantes:

Para enriquecer a aprendizagem; no entanto, a existência por si só de
um turno complementar não significa educação integral. [...] é preciso
manter em perspectiva a intencionalidade pedagógica, para que o
conjunto das atividades desenvolvidas dialogue com o currículo
escolar e corresponda à formação integral pretendida. Assim, deve-se
ter em vista o que se ensina e/o que se aprende no tempo expandido e
como gerir pedagogicamente esse tempo (UNICEF, 2011, p. 25).

Dessa forma, a professora proporciona aprendizagens por meio de situações que fazem parte do cotidiano das crianças e que fazem parte da realidade deles, das suas curiosidades. A professora tem uma observação permanente, procurando compreender as situações ocorridas para continuar planejando e pensando nos projetos que compõe o dia a dia das crianças.

Eu mantenho uma observação constante, eu tenho um diário de bordo, e eu tiro fotografias, que é uma ajuda potencial, porque depois eu consigo pensar por meio delas, eu consigo replanejar através delas (Professora da escola).

A importância da reflexão sobre a prática faz com que o professor repense suas atividades por meio das observações, das fotografias, tentando perceber, assim, como repercutiram os planejamentos, sendo estes lúdicos, os quais se aprende brincando, pois às vezes, durante a prática, não consegue compreender certas ações das crianças perante as atividades propostas. 
Freire (1996) deixa claro que a reflexão sobre a prática é fundamental para repensar os próximos planejamentos, “[...] na formação permanente dos professores, o momento fundamental é o da reflexão crítica sobre a prática. É pensando criticamente a prática de hoje ou de ontem que se pode melhorar a próxima prática" (Freire, 1996, p. 39).

Faz parte também da formação profissional do professor ter uma reflexão crítica sobre sua prática pedagógica realizada, podendo assim replanejar e repensar atitudes e situações que não foram adequadas, assim como repensar atitudes e situações que foram positivas, pois é uma forma de conhecer as crianças e poder contribuir com o processo de construção de interações e construção do conhecimento na infância.

Ser professor é um desafio! É um trabalho árduo de pensar e repensar a prática diariamente para que possa construir sua identidade profissional e construir a identidade da turma em que atua.

A necessidade familiar de trabalhar o dia todo para conquistar uma vida digna, uma boa educação para os filhos exige das famílias deixá-los no Turno Integral na Escola de Educação Infantil. Percebe-se que há o desejo da criança estar na escola e, ao mesmo tempo, de estar com a família. Há necessidade de o professor buscar compreender as situações e contribuir para as vivências e as aprendizagens destas crianças na escola. Também há necessidade da gestão escolar estar presente nesses momentos de adaptação das crianças na escola e na construção do desenvolvimento delas, para que seja levado em consideração o bem-estar das crianças nos espaços escolares.

O acompanhamento dos pais na escola é muito importante para os filhos. Sua participação e seu interesse pela educação dos filhos são fundamentais para o crescimento e desenvolvimento das crianças. Os pais retratam a procura e o interesse pelo Turno Integral em função de necessitarem trabalhar e não ter com quem deixar seus filhos, o qual se destaca como a mais importante das opções que levam a fazerem a escolha pelo Turno Integral para seus filhos na Educação Infantil.

Deixei na escola, por causa do meu trabalho. Eu não tinha com quem deixar e eu precisava trabalhar. No início ainda eu não trabalhava fixo assim, mas eu trabalhava duas, três vezes por semana. Mas daí mesmo assim como consegui a vaga, daí ela vinha. Quando eu comecei a trabalhar direto ela já ficou todos os dias sem problema nenhum assim (Mãe de uma aluna da escola). 
A necessidade dos pais, não significa que seja necessidade também das crianças. Por mais que elas gostem de estar na escola, de estar com os coleguinhas, com a "profe" eles gostariam de ter a oportunidade de ficar em casa com sua família. Hoje em dia, a necessidade de trabalhar e de dar sustentabilidade à família é fundamental, com isso, os pais, ou adultos familiares, acabam necessitando das turmas de Turno Integral, principalmente nas escolas de Educação Infantil, por não terem com quem deixar seus filhos e a Escola oferecer segurança, afeto, amor, atenção e, além de tudo, inúmeras interações desafiadoras para o desenvolvimento das crianças.

Nesta direção, a mãe que participou da pesquisa relata sua sensação ao deixar a filha na escola:

No início é difícil! A gente sente mais do que eles. Fico loca de medo de deixar ela e ela achar falta e no fim eles nem sentem tanta falta, a gente sente bem mais do que eles. A minha pelo menos foi assim bem tranquilo. Ela se adaptou bem e eu no começo tive um pouco de receio assim. Eu tinha medo, tenho até agora assim de se machucar, de irem para a pracinha e se machucar. Essa é minha preocupação maior assim (Mãe de uma aluna da escola).

Portanto, é necessário que sejam demonstrados sentimentos de cuidado e atenção aos pais das crianças. Eles querem que seus filhos sejam bem cuidados e, portanto, precisam sentir isso. Sendo assim, um dos compromissos do professor é o de ter dedicação com a profissão, passando aos pais a tranquilidade de que seus filhos estão protegidos e acolhidos no ambiente escolar.

Além disso, o professor que trabalha com turmas de Turno Integral necessita de um cuidado especial com a alimentação das crianças, pois estas fazem a maioria de suas refeições diárias na escola e, por estarem em fase de crescimento e desenvolvimento, necessitam de nutrientes necessários para ter uma boa saúde e disposição para brincar e aprender. Assim, a mãe relata suas preocupações em relação à alimentação da filha:

Ela requer um pouco de cuidado na alimentação! E eu também me preocupo com isso né, se ela comeu direitinho se não comeu, sempre pergunto para as gurias, ela comeu? Como é que foi? Porque ela é bem complicada assim para comer, mas ta tranquila (Mãe de uma aluna da escola).

Por intermédio dessa grande necessidade que os pais têm em precisar deixar seus filhos em uma boa escola, que os acolha bem, cuide bem de seu filho, para que ele possa 
trabalhar tranquilo, a professora da turma de Turno Integral comenta sobre as sensações e percepções que tem das crianças em meio a esta necessidade dos pais.

Eu percebo que talvez faça falta o vínculo familiar mais de perto, que quando tem muitos dias de chuva por exemplo, eles ficam estressados, que eles têm que ficar na sala, que não aconteceria numa casa, que as vezes tu tens dificuldades por exemplo assim numa criança que adoece e que precisaria de mais conforto que não tem na escola. Eu penso que o turno integral, tem dificuldades nessas crianças que não se alimentam. Eu tenho um que só come arroz... (Professora da escola).

A Professora da turma de Turno Integral precisa criar estratégias para que as crianças criem interesse em aproveitar e alimentar-se daquilo que é necessário para o crescimento delas. Assim, a Mãe de uma aluna que participou da entrevista relata:

Eu acho que é bom, acho que deveria ter mais turmas integrais, porque pra gente que trabalha fora é ótimo! E são bem, pelo menos aqui, são bem cuidadinhos. Claro que a gente se preocupa, mas sabe que estão bem cuidados. E ano que vem que não terá para a turma dela, ai complica bastante! Porque daí vou ter que ter uma pessoa para cuidar no horário que ela não ta aqui... E aí eu vou ver se tento ano que vem conseguir que ela continue aqui integral, porque tem uns casos aí que ficam, mas tem que pedir autorização judicial (Mãe de uma aluna da escola).

Dessa forma, é necessário pedir autorização judicial para que se cumpra a lei, sendo direito das crianças e dos pais que necessitam do Turno em Tempo Integral da escola, todavia, infelizmente, não há possibilidade de muitas crianças continuarem, para tanto seria necessária a ampliação dos espaços escolares para que estas crianças não fossem obrigadas a perder o vínculo.

Quanto ao tempo escolar, é o Turno em Tempo Integral em que as crianças permanecem na escola, o qual é pensado em relação aos eixos norteadores da Educação Infantil que são as interações, as brincadeiras, as atividades nos tempos e espaços da Educação Infantil.

A conversa realizada com os pequenos foi divertida, todos queriam participar, dar sua opinião e ouvir sua voz no gravador, mas apenas uma delas respondeu as perguntas, pois as outras ficaram com vergonha e acabaram não falando e não respondendo. Esperava-se muito ouvir todas, mas este é um assunto tão adulto para tratar com elas, que, ao fazer as perguntas, estas acabaram tornando-se diversão. 
Segundo as autoras, elas retratam as interações realizadas com as crianças e mencionam que:

\begin{abstract}
A sua participação pode adicionar algo a vida social, transformando-a. 'Dar voz às crianças' e evidenciar sua 'competência social' tornaramse procedimentos imperativos e incontornáveis na condução das investigações. Estas acepções passaram a integrar o discurso científico, ao tempo em que se diversificaram e multiplicaram os esforços para captar e revelar o 'ponto de vista' das crianças sobre os mais variados temas, reunindo-se, desse modo, uma infinidade de informações a respeito. Porém, tem sido extremamente difícil identificar, na prática, o que é esse algo que as crianças adicionam e qual o impacto e as conseqüências da sua ação na vida em sociedade. (NUNES e CARVALHO, 2007, p. 04).
\end{abstract}

A participação da criança no processo de investigar não se torna simples, pois, durante o processo de interação com as crianças, obteve-se apenas o relato de uma menina, mas que, mesmo assim, contribuiu para que a pesquisa pudesse ser realizada e compreendida por meio de suas ações e interações realizadas com a pesquisadora.

A menina que participou da entrevista diz gostar de estar e ficar na escola, porque a mãe trabalha, mas, ao mesmo tempo, demonstrou querer estar em casa com a mãe. Dessa forma, ao dizer que gosta de ficar na escola, mencionou que gosta de aprender e de ter um monte de brinquedos. Assim, percebe-se que há uma diferença da escola para a casa das crianças e que elas querem sim estar na escola, mas também querem ficar com sua família o tempo necessário que gostariam.

A criança que participou da entrevista conseguiu expressar em sua fala suas vivências significativas que pudessem contribuir com a pesquisa realizada, conseguindo organizar-se em seu pensamento. A professora da Turma Integral, comenta afirmando que busca compreender o que as crianças dizem em relação ao tempo que necessitam ficar na escola.

É a necessidade dos pais! Então o que acontece com essa turma integral, é dado pras mães que trabalham, as que não trabalham tem que optar pelo meio turno. As turmas integrais são para aqueles que não tem onde ficar. E então eu vejo pelo viés da necessidade. A escola proporciona para quem realmente precisa do turno integral (Professora da escola).

A necessidade sendo dos pais permite que a criança aceite permanecer na escola em Tempo Integral, mesmo que no início ela possa ser resistente, por não ter conhecido 
ainda a professora e se adaptado com ela. Como complemento, a professora da turma em Tempo Integral menciona que:

A adaptação do turno integral não é uma adaptação simples, é uma adaptação mais complexa do que uma criança que vem passar meio turno na escola. A adaptação de uma professora também não é muito fácil (Professora da escola).

A adaptação das crianças não é fácil e, consequentemente, a do Professor também não, pois é necessário que a criança possa conhecer-se nos espaços da sala de aula, nos ambientes da escola e também relacionar-se e interagir com a professora, para que assim possam criar vínculos afetivos, sendo estes construtivos para as aprendizagens e o desenvolvimento infantil.

Com o processo da pesquisa em andamento, sentiu-se a necessidade de compreender a quantidade de crianças que estão matriculadas nas EMEI's da cidade de Santa Maria. A seguir, um gráfico que representa a quantidade de crianças nestes espaços.

Gráfico 1: Representação das crianças nos espaços

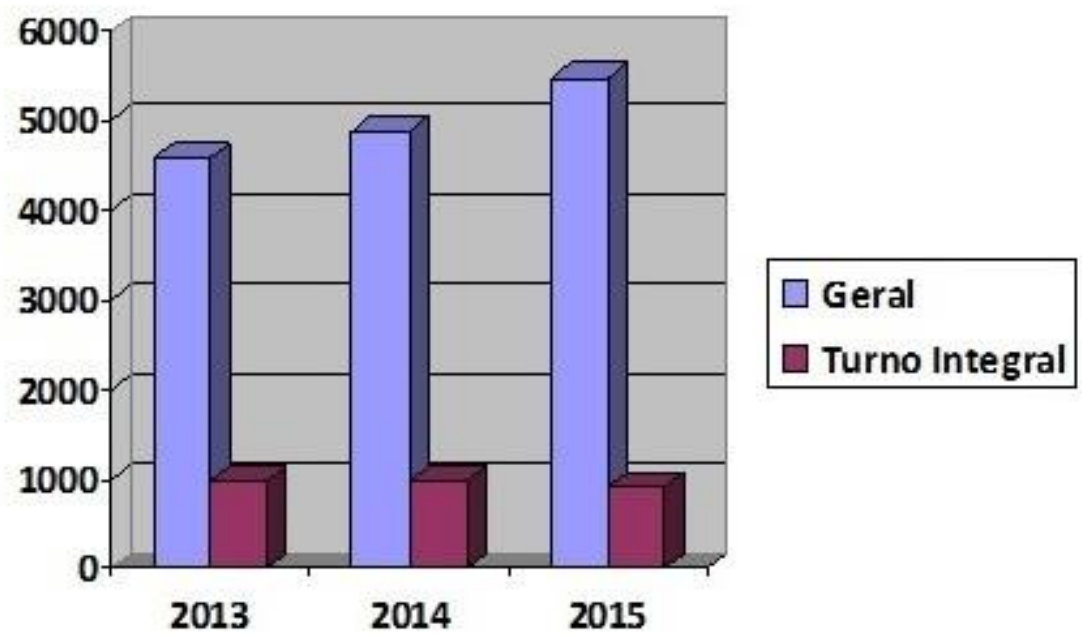

Fonte: Dados do censo escolar SMED (2015)

Por meio de dados da Secretaria Municipal de Educação (SMED, 2015), de acordo com o gráfico, do total de crianças, aproximadamente 4.000, em média 900 delas participam do Turno Integral na Educação Infantil nas escolas Municipais de Santa Maria, RS. 
Com esses dados, verifica-se que o número de crianças matriculadas no turno único cresceu consideravelmente e o número de crianças matriculadas no Turno Integral se manteve, concluindo-se ao término da pesquisa, que os espaços para o Turno Integral não foram ampliados, talvez mesmo por falta de espaço físico, porque o atendimento as crianças da Educação Infantil em Turno Integral não seja uma prioridade, visto que não houve a criação de uma única escola de Educação Infantil no município de Santa Maria nos últimos anos, mesmo tendo triplicado o número de crianças atendidas.

\section{Considerações finais}

Pesquisando a legislação que trata sobre a Educação em Tempo Integral, percebe-se que há ideias para que se realize esta oferta para todos os níveis, garantindo espaço e tempo adequados, mas que aos poucos estão sendo pensadas e priorizadas. Com o aumento do número de escolas de Educação Infantil, é possível que possa ser implementada melhor qualidade e atendimento às necessidades da população do município.

Muitas crianças, cujos pais necessitam do Turno Integral na Educação Infantil, não estão conseguindo vagas na escola, já que a prioridade maior passa a ser as vagas para turmas de turno único na instituição, deixando o Turno Integral ser prioridade para auxiliar nas necessidades da comunidade escolar. Contudo, essa é uma luta longa e muito árdua da sociedade em prol da defesa da garantia de acesso das crianças à escola em Turno Integral.

Na visão da diretora da escola investigada, a educação em Tempo Integral deve existir para as famílias que estão em situação de vulnerabilidade social, cabendo a nós criarmos estratégias para que todas as crianças tenham seu direito à Educação em Tempo Integral respeitado, sem que tenham que ser deixadas com adultos vizinhos ou em creches comunitárias.

Já a professora coloca em questão a necessidade dos pais trabalharem e não terem com quem deixar os filhos, e a escola proporcionar as vagas para quem precisa. No entanto, definir quem realmente precisa não é tarefa simples, envolve muitos fatores, pois todos os filhos de trabalhadores têm direito.

Destacando a necessidade dos pais para a existência do turno em Tempo Integral, principalmente nas escolas de Educação Infantil, em especial a escola onde foi 
realizada a pesquisa, a mãe acrescenta que deveriam ter mais turmas integrais na escola, entretanto isto não é possível devido à falta de espaço físico, não havendo possibilidade de crescimento das turmas. A escola gostaria muito e tem planos para o crescimento das turmas em Tempo Integral, que no futuro possa disponibilizar a todos os níveis o turno integral da escola, atendendo a necessidade dos pais e da comunidade escolar, o qual é de direito das famílias e das crianças.

A questão problema e o objetivo que motivaram o início desta pesquisa tinha por intenção compreender a proposta de trabalho elaborado e planejado para as crianças que frequentam a escola em Tempo Integral na educação infantil?

Com a pesquisa, compreendeu-se que a educação em Tempo Integral se destaca em meio à dinamicidade de ações realizadas pelas crianças juntamente com a professora e a gestão escolar, as quais pensam nos espaços que serão utilizados pelas crianças, embora não sejam muitos, nas interações ao longo do passar dos dias, vendo que tudo vale a pena quando se tem ações planejadas, propostas construtivas e a disponibilidade de criar novas possibilidades de para uma educação infantil mais amorosa e divertida.

Por fim, vale reafirmar que as crianças de 0 (zero) até os 6 (seis) anos de idade que necessitam do Turno Integral tem seu direito à Educação Integral de Tempo Integral asseguradas pela Constituição Federal do Brasil (1988). Sendo assim, a melhor solução pode não ser criar estratégias para retirar estas crianças da escola como vem sendo feito por nosso Estado, mas sim proporcionar espaços para que elas possam viver suas infâncias de forma plena de amor, cuidado e educação.

\section{Referências}

ARAÚJO, V. C. de; COELHO, G. R.; SIQUEIRA, L. de A. R. Educação em tempo integral na educação infantil: um estudo das concepções e praticas no estado do Espírito Santo/Brasil. Disponível em: <http://www.anpae.org.br/IBERO_AMERICANO_IV/GT1/GT1_Comunicacao/VaniaC arvalhodeAraujo_GT1_integral.pdf>. Acesso em: 15 jun. 2015.

BRASIL. Constituição da República Federativa do Brasil de 1998, Inciso XXV do art. $7^{\circ}$. Disponível em:

<http://www.planalto.gov.br/ccivil_03/Constituicao/Constituicao.htm> Acesso em: 18 out. 2015.

BRASIL. Diretrizes curriculares nacionais para a educação infantil. Ministério da Educação. Secretaria de Educação Básica. Brasília: MEC, SEB, 2010. 
BRASIL. Educação integral: texto referência para o debate nacional. Série Mais Educação. Brasília: Mec, Secad, 2009.

BRASIL. Lei de Diretrizes e Bases da Educação Nacional. Lei no 9.394, de 20 de dezembro de 1996.

BRASIL. Parecer CNB/CEB no 22/98. Ministério da Educação e do Desporto Conselho Nacional de Educação. Disponível em: <http://portal.mec.gov.br/dmdocuments/parecer_ceb_22.98.pdf> Acesso em: 14 Out. 2015.

BRASIL. Planejando a próxima década: Conhecendo as 20 metas do Plano Nacional de Educação. Ministério da Educação/Secretaria de Articulação com os Sistemas de Ensino (MEC/SASE), 2014.

COELHO, L. M. C. da C. Alunos no Ensino Fundamental, ampliação da jornada escolar e educação integral. UNIRIO. GT 13: 2011.

FREIRE, Paulo. Pedagogia da autonomia: saberes necessários à prática educativa. 39. ed. São Paulo: Paz e Terra, 1996.

KRAMER, S. Propostas pedagógicas ou curriculares: Subsídios para uma leitura crítica. In: Educação \& Sociedade, ano XVIII, n. 60, dezembro/97.

LÜCK, Heloísa. Gestão educacional: uma questão paradigmática. 4. ed. Petrópolis, RJ: Vozes, 2008b. Série Cadernos de Gestão.

NEVES, J. L. Pesquisa qualitativa: características, usos e possibilidades. Mestrando do curso de pós-graduação em administração de empresas. Disponível em: <http://www.ead.fea.usp.br/Cad-pesq/arquivos/C03-art06.pdf>. Acesso em: 01 set. 2015.

NUNES, Angela; CARVALHO, Maria Rosário de. Questões metodológicas e epistemológicas suscitadas pela antropologia da infância. (Artigo-ANPOCS/2007)

OSTETTO, L. E. Planejamento na Educação Infantil: mais que a atividade, a criança em foco. In: Encontros e encantamentos na educação infantil. Campinas, Papirus, 2000.

UNICEF. Tendências para a educação integral. "Iniciativa: Fundação Itaú Social, Fundo das Nações Unidas para a Infância” (UNICEF). São Paulo: Fundação Itaú Social CENPEC, 2011.

\section{Como referenciar este artigo}


WIEBUSCH; Andressa. Educação em tempo integral em uma escola de educação infantil de Santa Maria-RS: diálogos possíveis. Revista on line de Política e Gestão Educacional, Araraquara/SP, v.20, n.03, p. 579-599, 2016. Disponível em: <http://dx.doi.org/10.22633/rpge.v20.n3.9760>. ISSN: 1519-9029.

Submetido em: agosto/2016

Aprovado em: novembro/2016 